\title{
NK cell tolerance as the final endorsement of prenatal tolerance after in utero hematopoietic cellular transplantation
}

\section{OPEN ACCESS}

Edited by:

Tippi C. MacKenzie,

University of California,

San Francisco, USA

Reviewed by:

Graca Almeida-Porada,

Institute for Regenerative Medicine,

USA

William Hughes Peranteau,

The Children's Hospital of

Philade/phia, USA

*Correspondence:

Aimen F. Shaaban,

Center for Fetal Cellular and

Molecular Therapy and The

Department of Surgery, Cincinnati Children's Hospital Medical Center, 3333 Burnet Avenue, MLC 11025,

Cincinnati, OH 45229-3039, USA aimen.shaaban@cchmc.org

Specialty section:

This article was submitted to Integrative and Regenerative Pharmacology, a section of the journal

Frontiers in Pharmacology

Received: 05 December 2014 Accepted: 02 March 2015 Published: 18 March 2015

Citation:

Alhaijat AM, Lee AE, Strong BS and Shaaban AF (2015) NK cell tolerance as the final endorsement of prenatal tolerance after in utero hematopoietic

cellular transplantation.

Front. Pharmacol. 6:51.

doi: 10.3389/fphar.2015.00051

\begin{abstract}
Amir M. Alhajjat ${ }^{1}$, Amanda E. Lee ${ }^{2}$, Beverly S. Strong ${ }^{2}$ and Aimen F. Shaaban ${ }^{2 *}$
${ }^{1}$ Department of Surgery, University of lowa, lowa City, IA, USA, ${ }^{2}$ Center for Fetal Cellular and Molecular Therapy and The Department of Surgery, Cincinnati Children's Hospital Medical Center, Cincinnati, OH, USA
\end{abstract}

The primary benefits of in utero hematopoietic cellular transplantation (IUHCT) arise from transplanting curative cells prior to the immunologic maturation of the fetus. However, this approach has been routinely successful only in the treatment of congenital immunodeficiency diseases that include an inherent NK cell deficiency despite the existence of normal maternal immunity in either setting. These observations raise the possibility that fetal NK cells function as an early barrier to allogeneic IUHCT. Herein, we summarize the findings of previous studies of prenatal NK cell allospecific tolerance in mice and in humans. Cumulatively, this new information reveals the complexity of the fetal immune response in the setting of rejection or tolerance and illustrates the role for fetal NK cells in the final endorsement of allospecific prenatal tolerance.

Keywords: In utero transplantation, T cells, NK cells, fetus, tolerance, chimerism

In utero hematopoietic cellular transplantation (IUHCT) remains a promising intervention for treatment of a wide variety of congenital disease (Merianos et al., 2008). A primary assumption in IUHCT is that the early-gestation fetus has an immature immune system that is incapable of rejecting a donor cell transplant. As a result, the introduction of donor antigen prior to the development of the adaptive immunity should lead to life-long donor-specific tolerance. Thus, current protocols for IUHCT favor that the initial transplant be delivered by 12 weeks gestation within a "therapeutic window" that opens shortly after prenatal diagnosis and closes with thymic maturation (Westgren, 2006). Observations of naturally occurring hematopoietic chimeras demonstrates that, in essence, this is feasible (Owen, 1945). However, repeated clinical failure of IUHCT in the setting of a non-defective immune system has forced a re-examination of this central dogma, i.e., the translation of bedside observations back to the bench for hypothesis-driven inquiry.

\section{The Clinical Paradigm for Prenatal Transplantation}

Two related observations arising from clinical experience with IUHCT are in need of a scientific explanation. First, clinical application of IUHCT has documented success in the treatment of severe combined immunodeficiency (SCID). Indeed, the greatest clinical success has been realized in the treatment of NK cell deficient SCID (xSCID or ADA-SCID) whereas the use of IUHCT for the treatment of congenital diseases in which the fetal immune system is not defective has been uniformly unsuccessful (Touraine et al., 1992; Flake et al., 1996; Wengler et al., 1996) This includes most of the clinical experience with IUHCT for hemoglobinopathies such as sickle cell disease 
or thalassemia. Second, the maternal immune system has been intact for every case despite the nature of the clinical outcome (success or failure) suggesting no independent role for the maternal immune response in IUHCT-related engraftment failures. Taken together, these observations frame the clinical paradigm for IUHCT and serve as a template for translational study.

It has been postulated that competition between the donor and recipient cells for a limited number of available host hematopoietic stem cell (HSC) niches is responsible for the clinical failure of IUHCT in the treatment of hemoglobinopathy (Peranteau et al., 2004, 2006). Favorable competition with the host cells for available niches within the fetal liver or bone marrow is vital for successful engraftment and likely explains the enhanced clinical and experimental success of IUHCT with the use of more competitive fetal donor cells or larger doses of bone marrow cells (Shaaban and Flake, 1999; Peranteau et al., 2006; Shaaban et al., 2006). Improved competition for available host niches would logically lead to higher levels of early chimerism. Previous reports from our group illustrate that the early chimerism level (discussed below) is the major determinant of successful allogeneic engraftment and link this to the development of donorspecific NK cell tolerance (Shaaban et al., 2006; Durkin et al., 2008a,b; Alhajjat et al., 2013). However, a competitive-niche model struggles to explain the dichotomous observations for immunodeficient vs. non-immunodeficient cases and seems to disregard the obvious difference. More specifically, no direct evidence exists to support the existence of quantitative differences in the number of HSCs or available stem cell niches between the XSCID and sickle cell disease or $\beta$ thalassemia patients. To the contrary, the defects in SCID emerge following the lineage-specific differentiation of HSCs rather than during their maintenance or self-renewal (reviewed in Schmalstieg and Goldman, 2002; Kalman et al., 2004) As a result, the pre-thymic SCID fetal hematopoietic microenvironment should theoretically have the same frequency of available stem cell niches as in pre-thymic fetus with defective $\beta$-globin production and should engraft similarly if niche availability is the limiting factor. Therefore, a model in which donor cell competition for host niches solely determines the outcome of IUHCT does not adequately reconcile the clinical paradigm and prompts further study of early gestation fetal alloimmunity.

Studies in murine and primate models of IUHCT support the presence of an early gestation immune barrier to allotransplantation (Peranteau et al., 2007; Durkin et al., 2008a,b). In a murine study by Peranteau et al. (2007), both congenic and allogeneic transplant recipients demonstrated similar multi-lineage engraftment at 1 week of age. Thereafter, most allogeneic recipients lost engraftment (Peranteau et al., 2007). Similarly, we have also demonstrated that congenic recipients maintain long-term engraftment regardless of the chimerism level whereas allogeneic recipients require a minimum level of circulating chimerism to maintain stable engraftment and prevent a chronic form of rejection (Durkin et al., 2008b). Lastly, despite promising results in other large animal models (Lee et al., 2005; Vrecenak et al., 2014), numerous studies of allogeneic IUHCT in non-human primates have yield poor overall engraftment regardless of the gestational age (Cowan et al., 1996; Shields et al., 2003, 2004). In general, the use of fetal conditioning or mature $\mathrm{T}$ cell co-transplantation resulted in higher engraftment rates and chimerism levels overall (Peranteau et al., 2002; Hayashi et al., 2004; Ashizuka et al., 2006). Collectively, these findings point to the existence of a previously unrecognized immune barrier to IUHCT that resides within the fetal host potentially complicating the kinetics of early engraftment.

\section{Fetal T Cells are Unlikely to Act Alone in Rejection after IUHCT}

In the complexity of the developing fetus, successful prenatal engraftment likely requires that all components of the immune system develop tolerance. Similarly, failed engraftment in clinical cases that do not involve immunodeficiency likely results from a lack of tolerance in one or more components of the fetal immune response. In either case, an intrinsic immune barrier to prenatal allotransplantation exists within the fetal host and awaits further delineation. In the greater context, a better understanding of the critical parameters regulating the emergence of self-tolerance may explain the pattern of success and failure of IUHCT.

Previous studies reveal that $\mathrm{T}$ cell self-recognition is established before birth in most strains of mice including the C57BL6/J and Balb/c inbred strains. The first measurable indicator of self-recognition is the emergence of phenotypically mature $\mathrm{T}$ cells as early as E17 (Crispe et al., 1986). Phenotypically mature single-positive $\mathrm{T}$ cells have been found in the human thymus as early as 12 weeks gestation (Stites and Pavia, 1979; Haynes et al., 1989). Confirmation of the functional capacity to reject an allograft comes from transplant studies in newborn mice which do not accept fully allogeneic hematopoietic grafts without myeloablation or immunological preparation (Soper et al., 2003). Conversely, the capacity to reject allogeneic grafts does not exist earlier in gestation. The studies by Kim et al. $(1998,1999)$ first demonstrated that allospecific T cell tolerance can be reliably achieved by IUHCT to the murine fetus at E14 resulting in the deletion and anergy of donor-reactive $\mathrm{T}$ cells. Subsequent studies confirmed the allo-receptivity of C57BL/6 and Balb/c fetuses at E14 (Shaaban et al., 1999, 2006; Hayashi et al., 2002;Durkin et al., 2008a,b; Alhajjat et al., 2013; Nijagal et al., 2013). Collectively, these findings suggest that the potential for donor-specific tolerance to reliably develop following IUHCT is lost shortly after the appearance of mature single positive $\mathrm{T}$ cells.

Furthermore, in the studies by Kim et al. $(1998,1999)$, T cell and skin allograft tolerance could be seen with extremely low levels of microchimerism ( $<0.1 \%)$ following IUHCT between MHC class I-matched or mismatched strain combinations. These findings seem to conflict with subsequent studies (Ashizuka et al., 2006; Durkin et al., 2008b) demonstrating that tolerance to a hematopoietic graft tolerance requires macrochimerism (1-2\%) but may be reconciled through an understanding of the different measures of tolerance. Skin-graft acceptance has been 
shown to reflect $\mathrm{T}$ cell rather than NK cell tolerance whereas tolerance to a hematopoietic graft reflects both. NK cells fail to reject allogeneic skin grafts in the absence of IL-15 activation (Kroemer et al., 2008). Thus in sub-threshold microchimeric mice, host $\mathrm{T}$ cells may be tolerant to allogeneic skin grafts while host NK cells are not tolerant to allogeneic hematopoietic cells. Additionally, although NK maturation occurs in the early second trimester of human gestation, it continues for several weeks after birth in the B6 mouse (Dorfman and Raulet, 1998). In the aforementioned studies by Kim et al. (1998, 1999), the majority of skin grafts were placed on the microchimeric mice during the prolonged phase of chronic rejection that is typical of low-level prenatal chimerism. As such some degree of hyporesponsiveness to skin and possibly hematopoietic grafts likely exists during this rejection period. Comparative measurements of the allospecific response between $\mathrm{T}$ cells and NK cells in microchimeric or sub-threshold chimeric mice might reveal these differences. Thus, the existence of hematopoietic microchimerism during that period appears to be sufficient for donor-specific $\mathrm{T}$ cell and skin allograft tolerance to develop but insufficient for NK cell tolerance. As such, the potential for either $\mathrm{T}$ cell tolerance or rejection to develop following IUHCT seems to hinge on the timing of transplant rather than the level of chimerism. Perhaps these differences arise from the relatively high-affinity interactions between $\mathrm{T}$ cell receptors and peptide-MHC complexes (TCR-pMHC) that regulate much of thymic selection (reviewed in Moran and Hogquist, 2012; Morris and Allen, 2012). Given the high cell dose per $\mathrm{kg}$ of fetal body mass previously used for clinical IUHCT, it is likely that sufficient chimerism levels were present for the induction of $\mathrm{T}$ cell tolerance. As such, $\mathrm{T}$ cell-mediated rejection seems to be an inadequate stand-alone explanation for the failed engraftment seen in the treatment of hemoglobinopathy by IUHCT.

\section{Fetal NK Cells as an Intrinsic Barrier to Prenatal Allotransplantation and a Target for Immunotherapy}

The presence of a secondary barrier to prenatal engraftment mediated by fetal NK cells would explain the clinical pattern of enhanced success in NK cell deficient recipients (Flake et al., 1996; Wengler et al., 1996; Archer et al., 1997). An NK cell barrier would also explain the delayed experimental engraftment loss (chronic rejection) previously reported by multiple investigators (Carrier et al., 2000; Donahue et al., 2001; Peranteau et al., 2007; Durkin et al., 2008b) as this coincides temporally with the maturation of NK cell allorecognition (Roth et al., 2000). For these reasons, we queried the response of NK cells in a murine model and ultimately confirmed the existence of an NK cell-mediated barrier to the engraftment of prenatally transplanted allogeneic hematopoietic cells (Figure 1). Importantly, this barrier was found to be critically dependent on the level of circulating chimerism (Durkin et al., 2008b). With high levels of chimerism, recipients maintained stable engraftment and exhibited donorspecific NK cell tolerance. Conversely, recipients with low chimerism levels displayed NK cell-dependent chronic graft rejection.

The essence of this quantitative model for NK cell education is that the donor-specific tolerance requires a threshold level of

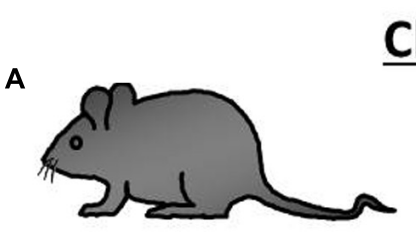

Chimerism Level
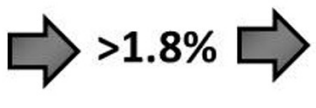

B
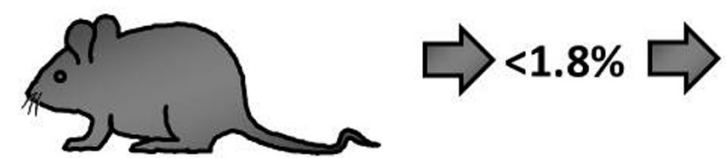

C

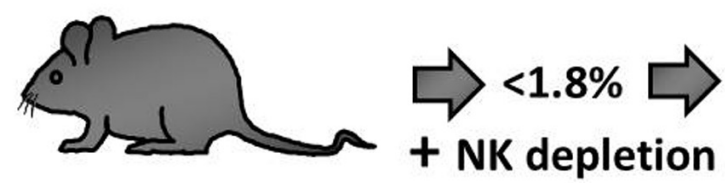

Outcome

$100 \%$

Tolerance/Engraftment Engrafter
FIGURE 1 | The outcome of engraftment or rejection following allogeneic In utero hematopoietic cellular transplantation (IUHCT) is predicted by the early chimerism level and hinges on the development of NK cell tolerance. (A) Mice with an early chimerism level above the chimerism threshold (Engrafter mice; $>1.8 \%$ circulating chimerism) exhibit durable long-term multi-lineage engraftment. (B) With early chimerism levels below the chimerism threshold, NK cell tolerance does not develop and universal rejection occurs (Rejecter mice; <1.8\% circulating chimerism). (C) Rejection is abrogated when NK cells are depleted in rejecter mice thereby rescuing prenatal engraftment (Rescued Engrafter mice). 
exposure to the donor ligands during development - a chimerism threshold ( $>1.8 \%)$. Remarkably, we found that the chimerism threshold reliably predicts the binary outcome of either engraftment or rejection which is the arguably most meaningful measure of prenatal tolerance induction. Furthermore, the chimerism threshold proved to be irrelevant in IUHCT between congenic strains of mice which are immunologically matched reducing the likelihood that limiting-dilution kinetics were the cause of failed engraftment below the chimerism threshold (Durkin et al., 2008b). Lastly, we demonstrated that the engraftment loss can be prevented in sub-threshold chimeras by early in vivo depletion of host NK cells (Figure 1). During the period of NK cell depletion, chimerism levels remained stable or increased slightly. When the host NK cells were allowed to return following withdrawal of the depleting antibody, abrupt rejection was observed in all of the animals. These findings defined a critical relationship between a threshold level of donor chimerism and the development of donor-specific NK cell tolerance. In a larger context, the significance of this threshold lies in the identification of the minimum level of antigen exposure during the $\mathrm{T}$ and NK cell education that is necessary for durable recognition as self.

\section{Trogocytosis as a Mechanistic Link between the Chimerism Threshold and Prenatal NK Cell Tolerance}

In order for prenatal tolerance to develop at such low levels of chimerism (1.8\%), the process of self-education should include a mechanism to compensate for the low probability of effector cells to encounter appreciable levels of donor ligand. We have recently reported that donorto-host MHC transfer (trogocytosis) might function in this role (Alhajjat et al., 2013). Trogocytosis of donor MHC may permit sustained cis-recognition of the donor ligands during development in the absence of trans-interaction directly with the donor cells or with host APC's. The cis-recognition of donor antigens by tolerant host NK cells may selectively prevent the apoptosis of "friendly" phenotypes during the selection of the mature NK cell repertoire. Support for this mechanism comes from the recent report by Brodin et al. (2012) who examined Ly49D $+\mathrm{NK}$ cells in H-2D ${ }^{\mathrm{d}}$ transgenic B6 mice and found that the co-expression of Ly49A conferred a resistance to apoptosis. Consistent with this postulate, high levels of trogocytosis were found on the surface of phenotypically friendly NK cells that express donor-specific inhibitory receptors when compared to the phenotypically hostile NK cells that do not express these inhibitory receptors. Subsequent to their developmental selection, the cis-recognition of transferred donor-MHC by phenotypically friendly NK cells might provide a continuous exposure to the donor ligands affecting their maturation, survival and function (Kim et al., 2005; Chalifour et al., 2009). In this manner, trogocytosis of donor ligands could provide an intrinsic mechanism for the development and maintenance of donor-specific NK cell tolerance.

\section{Fetal NK Cells at the Interface with the Maternal Immune System}

A maternal immune response toward the donor cells has been proposed as a barrier to prenatal allo-transplantation resulting in the delayed chronic rejection of the donor graft (Merianos et al., 2009; Nijagal et al., 2011). As discussed earlier, this postulate is inconsistent with the recurring clinical observation that IUHCT has been successful in cases where the maternal immune response was intact but the fetal immune system was defective (Flake et al., 1996; Wengler et al., 1996; Merianos et al., 2008). Also incompatible with this conclusion is the observation that engraftment or rejection after IUHCT occurs in littermates subjected to the same maternal influence (Durkin et al., 2008b; Merianos et al., 2009). Lastly, the in vivo elimination of host NK cells prevents the chronic rejection seen in sub-threshold chimeras and establishes that the effectors of this response reside within the fetal recipient. Collectively, these findings argue against the existence of a clinically relevant maternal immune barrier to IUHCT and should be reconciled with those of previous reports concluding that a maternal immune response toward the transplanted cells leads to engraftment loss in allogeneic IUHCT.

In the study by Merianos et al. (2009), prenatal allogeneic chimeras were noted to lose engraftment at a relatively high rate several weeks after birth. When naïve foster dams were used after delivery, no engraftment loss occurred. This observation was explained by the finding of donor-specific alloantibodies in the maternal breast milk that perhaps induced graft rejection after birth. The authors provided no data regarding the level of chimerism in the animals that rejected their graft. Additionally, the presence of maternal alloantibodies did not result in graft rejection in nearly $1 / 3$ of the littermates of the pups that lost engraftment suggesting some heterogeneity in the effect of the maternal immune response.

These findings may relate to the experimental methodology employed in their study. The study by Merianos et al. (2009) used very large doses of adult donor bone marrow cells $\left(20 \times 10^{6}\right.$ cells/fetus) which provided a large number of mature $\mathrm{T}$ cells to the fetus (approximately $10^{9}$ mature T cells $/ \mathrm{kg}$ ). These large $\mathrm{T}$ cell doses may have resulted in a significant graft-vs-host reaction that may have diminished the maternal-fetal immune barrier leading to a greater exposure of the fetal cells to the maternal immune system. The high chimerism levels seen in this model likely compounded the exposure to the donor alloantigens leading to a functionally significant maternal immune response and precipitous fetal loss. Conversely, mature T cells are absent from the fetal liver donor cell populations used in other studies and chimerism levels are much more modest at the lower doses that were used (Rebel et al., 1996; Szilvassy et al., 2001; Taylor et al., 2002; Hayashi et al., 2003). Further study is necessary to confirm the potential to provoke a maternal humoral response with the use of large T cell doses or high early chimerism levels in IUHCT.

These possibilities are further supported by the study of Nijagal et al. (2011), which utilized fetal liver cells for prenatal transplantation and found that the use of naïve foster dams had no impact on delayed engraftment loss. Instead, the authors observed that a significant numbers of $\mathrm{T}$ cells traffic from the 
mother into the fetus following prenatal transplantation and proposed that a maternal $\mathrm{T}$ cell response was responsible for the lower early engraftment rates in allogeneic vs. congenic IUHCT. Indeed, higher engraftment rates were seen with the use of $\mathrm{T}$ cell deficient mothers or by matching the donor cells with the maternal MHC antigens in wild-type matings thereby avoiding the potential for a maternal $\mathrm{T}$ cell response in either setting.

However, the reported early engraftment rate in this study is unusually low given the relatively large number of transplanted fetal liver cells. Using the same methodology to prepare and prenatally transplant a similar dose of MHC mismatched fetal liver donor cells $\left(2 \times 10^{6}\right.$ cells/fetus $)$ in this strain combination, we have reliably detected engraftment in $100 \%$ of the offspring despite the use of immunologically normal wild-type dams (Durkin et al., 2008b). The reasons for the different engraftment rates between the two studies are unclear but may result from differences in the strain combination or technical variations in the transplant procedure. Additionally, the authors concluded that maternal $\mathrm{T}$ cells persisted in the chimeric offspring for months after birth and led to chronic rejection. However, no maternal cells could be found within the recipient at any point beyond the fetal period making it difficult to reconcile engraftment loss by this mechanism that occurred months later. Despite these unresolved issues, the finding of maternal cells in the fetal immune system illustrates the potential complexities involved in prenatal transplantation and clearly warrants further study.

\section{Early Gestation Human Fetal NK Cells Possess the Capacity for Allorecognition and the Potential to Respond to Prenatal Allo-Transplantation}

The gestational time frame in which human fetal NK cells develop the capacity for allorecognition has not been directly elucidated. The finding of mature cytotoxic NK cells in human cord blood provides clear evidence that this occurs prior to birth (Wang et al., 2007). It is conceivable that this coincides with acquisition of killer immunoglobulin-like receptors (KIR) similar to the acquisition of the homologous Ly49 NK cell receptors

\section{References}

Alhajjat, A. M., Durkin, E. T., and Shaaban, A. F. (2010). Regulation of the earliest immune response to in utero hematopoietic cellular transplantation. Chimerism 1, 61-63. doi: 10.4161/chim.1.2.13147

Alhajjat, A. M., Strong, B. S., Durkin, E. T., Turner, L. E., Wadhwani, R. K., Midura, E. F., et al. (2013). Trogocytosis as a mechanistic link between chimerism and prenatal tolerance. Chimerism 4, 126-131. doi: 10.4161/chim. 26666

Anfossi, N., Andre, P., Guia, S., Falk, C. S., Roetynck, S., Stewart, C. A., et al. (2006). Human NK cell education by inhibitory receptors for MHC class I. Immunity 25, 331-342. doi: 10.1016/j.immuni.2006.06.013

Archer, D. R., Turner, C. W., Yeager, A. M., and Fleming, W. H. (1997). Sustained multilineage engraftment of allogeneic hematopoietic stem cells in NOD/SCID mice after in utero transplantation. Blood 90, 3222-3229. in mice (Roth et al., 2000). Acquisition of Ly49 receptors is commensurate with development of mature cytotoxic capacity and temporally coincides with rejection in sub-threshold chimeras or tolerance and engraftment in above threshold chimeras (Anfossi et al., 2006; Durkin et al., 2008b; Orr and Lanier, 2010). In a seminal report by Phillips et al. (1992), NK cells were found in human fetal liver as early as 6 weeks and in fetal spleen by 15 weeks of gestation. Similar to observations in fetal mice, these early human fetal liver NK cells were found to express high levels of the class Ib-specific CD94/NKG2 receptors. However, an analysis for the expression of the class Ia-specific KIR receptors was not included. The in vitro study of differentiating CD34+ hematopoietic progenitors indicates that CD94/NKG2A expression precedes the expression of HLA-specific KIR receptors by human NK cells (Grzywacz et al., 2006). For this reason, we examined the expression of KIR receptors by early gestation human fetal NK cells and found that small subsets of human fetal NK cells express adult levels of KIR receptor by 10 weeks of gestation with more appreciable levels identified by 14 weeks gestation (Alhajjat et al., 2010). A subsequent report by Ivarsson et al. (2013), demonstrated paradoxical hyporesponsivness to KIRspecific stimulation of second trimester human fetal NK cells. Hence, although early gestation human fetal NK cells possess the necessary machinery for allorecognition, a confirmation of their capacity for allospecific cytotoxicity requires future study.

\section{Closing Remarks}

Successful engraftment in IUHCT likely requires tolerance in all components of the host immune system. Our studies in the murine model have indicated that a minimum level of circulating ligand is necessary to induce and maintain tolerance. This level seems to be higher for NK cells than the level required for other components of the immune system. Thus, the chimerism threshold might represent the minimum qualification in the education of the developing NK cells and NK cell tolerance as the final endorsement of donor recognition. The study of NK cell repertoire formation, maturity, and trogocytosis in prenatal transplantation will not only facilitate understanding of the NK cell barrier, but will also contribute to the overall understanding of NK cell biology.

Ashizuka, S., Peranteau, W. H., Hayashi, S., and Flake, A. W. (2006). Busulfanconditioned bone marrow transplantation results in high-level allogeneic chimerism in mice made tolerant by in utero hematopoietic cell transplantation. Exp. Hematol. 34, 359-368. doi: 10.1016/j.exphem.2005.11.011

Brodin, P., Lakshmikanth, T., Karre, K., and Hoglund, P. (2012). Skewing of the NK cell repertoire by MHC class I via quantitatively controlled enrichment and contraction of specific Ly49 subsets. J. Immunol. 188, 2218-2226. doi: 10.4049/jimmunol.1102801

Carrier, E., Gilpin, E., Lee, T. H., Busch, M. P., and Zanetti, M. (2000). Microchimerism does not induce tolerance after in utero transplantation and may lead to the development of alloreactivity. J. Lab. Clin. Med. 136, 224-235. doi: $10.1067 / \mathrm{mlc} .2000 .108942$

Chalifour, A., Scarpellino, L., Back, J., Brodin, P., Devevre, E., Gros, F., et al. (2009). A Role for cis Interaction between the Inhibitory Ly49A receptor and MHC class I for natural killer cell education. Immunity 30, 337-347. doi: 10.1016/j.immuni.2008.12.019 
Cowan, M. J., Tarantal, A. F., Capper, J., Harrison, M., and Garovoy, M. (1996). Long-term engraftment following in utero $\mathrm{T}$ cell-depleted parental marrow transplantation into fetal rhesus monkeys. Bone Marrow Transplant. 17, 1157 1165.

Crispe, I. N., Husmann, L. A., and Bevan, M. J. (1986). T cell receptor expression and receptor-mediated induction of clonal growth in the developing mouse thymus. High surface beta-chain density is a requirement for functional maturity. Eur. J. Immunol. 16, 1283-1288. doi: 10.1002/eji.1830161016

Donahue, J., Gilpin, E., Lee, T. H., Busch, M. P., Croft, M., and Carrier, E. (2001). Microchimerism does not induce tolerance and sustains immunity after in utero transplantation. Transplantation 71, 359-368. doi: 10.1097/00007890200102150-00004

Dorfman, J. R., and Raulet, D. H. (1998). Acquisition of Ly49 receptor expression by developing natural killer cells. J. Exp. Med. 187, 609-618. doi: 10.1084/jem.187.4.609

Durkin, E. T., Jones, K. A., Elnaggar, D., and Shaaban, A. F. (2008a). Donor major histocompatibility complex class I expression determines the outcome of prenatal transplantation. J. Pediatr. Surg. 43, 1142-1147. doi: 10.1016/j.jpedsurg.2008.02.046

Durkin, E. T., Jones, K. A., Rajesh, D., and Shaaban, A. F. (2008b). Early chimerism threshold predicts sustained engraftment and NK-cell tolerance in prenatal allogeneic chimeras. Blood 112, 5245-5253. doi: 10.1182/blood-2007-12-128116

Flake, A. W., Roncarolo, M. G., Puck, J. M., Almeida-Porada, G., Evans, M. I., Johnson, M. P., et al. (1996). Treatment of X-linked severe combined immunodeficiency by in utero transplantation of paternal bone marrow. N. Engl. J. Med. 335, 1806-1810. doi: 10.1056/NEJM199612123352404

Grzywacz, B., Kataria, N., Sikora, M., Oostendorp, R. A., Dzierzak, E. A., Blazar, B. R., et al. (2006). Coordinated acquisition of inhibitory and activating receptors and functional properties by developing human natural killer cells. Blood 108, 3824-3833. doi: 10.1182/blood-2006-04-020198

Hayashi, S., Abdulmalik, O., Peranteau, W. H., Ashizuka, S., Campagnoli, C., Chen, Q., et al. (2003). Mixed chimerism following in utero hematopoietic stem cell transplantation in murine models of hemoglobinopathy. Exp. Hematol. 31, 176-184. doi: 10.1016/S0301-472X(02)01024-X

Hayashi, S., Hsieh, M., Peranteau, W. H., Ashizuka, S., and Flake, A. W. (2004). Complete allogeneic hematopoietic chimerism achieved by in utero hematopoietic cell transplantation and cotransplantation of LLME-treated, MHC-sensitized donor lymphocytes. Exp. Hematol. 32, 290-299. doi: 10.1016/j.exphem.2003.12.008

Hayashi, S., Peranteau, W. H., Shaaban, A. F., and Flake, A. W. (2002). Complete allogeneic hematopoietic chimerism achieved by a combined strategy of in utero hematopoietic stem cell transplantation and postnatal donor lymphocyte infusion. Blood 100, 804-812. doi: 10.1182/blood-2002-01-0016

Haynes, B. F., Denning, S. M., Singer, K. H., and Kurtzberg, J. (1989). Ontogeny of T-cell precursors: a model for the initial stages of human T-cell development. Immunol. Today 10, 87-91. doi: 10.1016/0167-5699(89)90232-6

Ivarsson, M. A., Loh, L., Marquardt, N., Kekalainen, E., Berglin, L., Bjorkstrom, N. K., et al. (2013). Differentiation and functional regulation of human fetal NK cells. J. Clin. Invest. 123, 3889-3901. doi: 10.1172/JCI68989

Kalman, L., Lindegren, M. L., Kobrynski, L., Vogt, R., Hannon, H., Howard, J. T., et al. (2004). Mutations in genes required for T-cell development: IL7R, CD45, IL2RG, JAK3, RAG1, RAG2, ARTEMIS, and ADA and severe combined immunodeficiency: HuGE review. Genet. Med. 6, 16-26. doi: 10.1097/01.GIM.0000105752.80592.A3

Kim, H. B., Shaaban, A. F., Milner, R., Fichter, C., and Flake, A. W. (1999). In utero bone marrow transplantation induces donor-specific tolerance by a combination of clonal deletion and clonal anergy. J. Pediatr. Surg. 34, 726-730. doi: 10.1016/S0022-3468(99)90364-0

Kim, H. B., Shaaban, A. F., Yang, E. Y., Liechty, K. W., and Flake, A. W. (1998). Microchimerism and tolerance after in utero bone marrow transplantation in mice. J. Surg. Res. 77, 1-5. doi: 10.1006/jsre.1997.5255

Kim, S., Poursine-Laurent, J., Truscott, S. M., Lybarger, L., Song, Y. J., Yang, L., et al. (2005). Licensing of natural killer cells by host major histocompatibility complex class I molecules. Nature 436, 709-713. doi: 10.1038/nature03847

Kroemer, A., Xiao, X., Degauque, N., Edtinger, K., Wei, H., Demirci, G., et al. (2008). The innate NK cells, allograft rejection, and a key role for IL-15. J. Immunol. 180, 7818-7826. doi: 10.4049/jimmunol.180.12.7818
Lee, P. W., Cina, R. A., Randolph, M. A., Arellano, R., Goodrich, J., Rowland, H., et al. (2005). In utero bone marrow transplantation induces kidney allograft tolerance across a full major histocompatibility complex barrier in Swine. Transplantation 79, 1084-1090. doi: 10.1097/01.TP.0000161247.61727.67

Merianos, D., Heaton, T., and Flake, A. W. (2008). In utero hematopoietic stem cell transplantation: progress toward clinical application. Biol. Blood Marrow Transplant. 14, 729-740. doi: 10.1016/j.bbmt.2008.02.012

Merianos, D. J., Tiblad, E., Santore, M. T., Todorow, C. A., Laje, P., Endo, M., et al. (2009). Maternal alloantibodies induce a postnatal immune response that limits engraftment following in utero hematopoietic cell transplantation in mice. J. Clin. Invest. 119, 2590-2600. doi: 10.1172/JCI38979

Moran, A. E., and Hogquist, K. A. (2012). T-cell receptor affinity in thymic development. Immunology 135, 261-267. doi: 10.1111/j.1365-2567.2011. 03547.x

Morris, G. P., and Allen, P. M. (2012). How the TCR balances sensitivity and specificity for the recognition of self and pathogens. Nat. Immunol. 13, 121-128. doi: 10.1038/ni.2190

Nijagal, A., Derderian, C., Le, T., Jarvis, E., Nguyen, L., Tang, Q., et al. (2013). Direct and indirect antigen presentation lead to deletion of donor-specific T cells after in utero hematopoietic cell transplantation in mice. Blood 121, 4595-4602. doi: 10.1182/blood-2012-10-463174

Nijagal, A., Wegorzewska, M., Jarvis, E., Le, T., Tang, Q., and MacKenzie, T. C. (2011). Maternal T cells limit engraftment after in utero hematopoietic cell transplantation in mice. J. Clin. Invest. 121, 582-592. doi: 10.1172/JCI44907

Orr, M. T., and Lanier, L. L. (2010). Natural killer cell education and tolerance. Cell 142, 847-856. doi: 10.1016/j.cell.2010.08.031

Owen, R. D. (1945). Immunogenetic consequences of vascular anatomoses between bovine twins. Science 102, 400-401. doi: 10.1126/science.102.2651.400

Peranteau, W. H., Endo, M., Adibe, O. O., and Flake, A. W. (2007). Evidence for an immune barrier after in utero hematopoietic-cell transplantation. Blood 109, 1331-1333. doi: 10.1182/blood-2006-04-018606

Peranteau, W. H., Endo, M., Adibe, O. O., Merchant, A., Zoltick, P. W., and Flake, A. W. (2006). CD26 inhibition enhances allogeneic donor-cell homing and engraftment after in utero hematopoietic-cell transplantation. Blood 108, 4268-4274. doi: 10.1182/blood-2006-04-018986

Peranteau, W. H., Hayashi, S., Hsieh, M., Shaaban, A. F., and Flake, A. W. (2002). High-level allogeneic chimerism achieved by prenatal tolerance induction and postnatal nonmyeloablative bone marrow transplantation. Blood 100, 2225-2234. doi: 10.1182/blood-2002-01-0166

Peranteau, W. H., Hayashi, S., Kim, H. B., Shaaban, A. F., and Flake, A. W. (2004). In utero hematopoietic cell transplantation: what are the important questions? Fetal Diagn. Ther. 19, 9-12. doi: 10.1159/000074253

Phillips, J. H., Hori, T., Nagler, A., Bhat, N., Spits, H., and Lanier, L. L. (1992). Ontogeny of human natural killer (NK) cells: fetal NK cells mediate cytolytic function and express cytoplasmic CD3 epsilon, delta proteins. J. Exp. Med. 175, 1055-1066. doi: 10.1084/jem.175.4.1055

Rebel, V. I., Miller, C. L., Eaves, C. J., and Lansdorp, P. M. (1996). The repopulation potential of fetal liver hematopoietic stem cells in mice exceeds that of their liver adult bone marrow counterparts. Blood 87, 3500-3507.

Roth, C., Carlyle, J. R., Takizawa, H., and Raulet, D. H. (2000). Clonal acquisition of inhibitory Ly49 receptors on developing NK cells is successively restricted and regulated by stromal class I MHC. Immunity 13, 143-153. doi: 10.1016/S1074-7613(00)00015-7

Schmalstieg, F. C., and Goldman, A. S. (2002). Immune consequences of mutations in the human common gamma-chain gene. Mol. Genet. Metab. 76, 163-171. doi: 10.1016/S1096-7192(02)00042-2

Shaaban, A. F., and Flake, A. W. (1999). Fetal hematopoietic stem cell transplantation. Semin. Perinatol. 23, 515-523. doi: 10.1016/S0146-0005(99) 80030-5

Shaaban, A. F., Kim, H. B., Gaur, L., Liechty, K. W., and Flake, A. W. (2006). Prenatal transplantation of cytokine-stimulated marrow improves early chimerism in a resistant strain combination but results in poor longterm engraftment. Exp. Hematol. 34, 1278-1287. doi: 10.1016/j.exphem.2006. 05.007

Shaaban, A. F., Kim, H. B., Milner, R., and Flake, A. W. (1999). A kinetic model for the homing and migration of prenatally transplanted marrow. Blood 94, 3251-3257. 
Shields, L. E., Gaur, L., Delio, P., Potter, J., Sieverkropp, A., and Andrews, R. G. (2004). Fetal immune suppression as adjunctive therapy for in utero hematopoietic stem cell transplantation in nonhuman primates. Stem Cells 22, 759-769. doi: 10.1634/stemcells.22-5-759

Shields, L. E., Gaur, L. K., Gough, M., Potter, J., Sieverkropp, A., and Andrews, R. G. (2003). In utero hematopoietic stem cell transplantation in nonhuman primates: the role of T cells. Stem Cells 21, 304-314. doi: 10.1634/stemcells.213-304

Soper, B. W., Lessard, M. D., Jude, C. D., Schuldt, A. J., Bunte, R. M., and Barker, J. E. (2003). Successful allogeneic neonatal bone marrow transplantation devoid of myeloablation requires costimulatory blockade. J. Immunol. 171, 3270-3277. doi: 10.4049/jimmunol.171.6.3270

Stites, D. P., and Pavia, C. S. (1979). Ontogeny of human T cells. Pediatrics 64(Suppl. 2), 795-802.

Szilvassy, S. J., Meyerrose, T. E., Ragland, P. L., and Grimes, B. (2001). Differential homing and engraftment properties of hematopoietic progenitor cells from murine bone marrow, mobilized peripheral blood, and fetal liver. Blood 98, 2108-2115. doi: 10.1182/blood.V98.7.2108

Taylor, P. A., McElmurry, R. T., Lees, C. J., Harrison, D. E., and Blazar, B. R. (2002). Allogenic fetal liver cells have a distinct competitive engraftment advantage over adult bone marrow cells when infused into fetal as compared with adult severe combined immunodeficient recipients. Blood 99, 1870-1872. doi: 10.1182/blood.V99.5.1870

Touraine, J. L., Raudrant, D., Rebaud, A., Roncarolo, M. G., Laplace,S., Gebuhrer, L., et al. (1992). In utero transplantation of stem cells in humans: immunological aspects and clinical follow-up of patients. Bone Marrow Transplant. 9(Suppl. 1), 121-126.
Vrecenak, J. D., Pearson, E. G., Santore, M. T., Todorow, C. A., Li, H., Radu, A., et al. (2014). Stable long-term mixed chimerism achieved in a canine model of allogeneic in utero hematopoietic cell transplantation. Blood 124, 1987-1995. doi: 10.1182/blood-2013-11537571

Wang, Y. Y., Xu, H., Zheng, X. D., Wei, H. M., Sun, R., and Tian, Z. G. (2007). High expression of NKG2A/CD94 and low expression of granzyme B are associated with reduced cord blood NK cell activity. Cell. Mol. Immunol. 4, 377-382.

Wengler, G. S., Lanfranchi, A., Frusca, T., Verardi, R., Neva, A., Brugnoni, D., et al. (1996). In-utero transplantation of parental CD34 haematopoietic progenitor cells in a patient with X-linked severe combined immunodeficiency (SCIDXI). Lancet 348, 1484-1487. doi: 10.1016/S0140-6736(96) 09392-0

Westgren, M. (2006). In utero stem cell transplantation. Semin. Reprod. Med. 24, 348-357. doi: 10.1055/s-2006-952156

Conflict of Interest Statement: The authors declare that the research was conducted in the absence of any commercial or financial relationships that could be construed as a potential conflict of interest.

Copyright (c) 2015 Alhajjat, Lee, Strong and Shaaban. This is an open-access article distributed under the terms of the Creative Commons Attribution License (CC BY). The use, distribution or reproduction in other forums is permitted, provided the original author(s) or licensor are credited and that the original publication in this journal is cited, in accordance with accepted academic practice. No use, distribution or reproduction is permitted which does not comply with these terms. 